Revista Arbitrada Interdisciplinaria KOINONIA

Año V. Vol V. N¹0. Julio - Diciembre 2020

Hecho el depósito de Ley: FA2016000010

ISSN: 2542-3088

FUNDACIÓN KOINONIA (F.K). Santa Ana de Coro. Venezuela.

Karina Monserrath Siguenza-Peñafiel; Juan Carlos Erazo-Álvarez; Cecilia Ivonne Narváez-Zurita

http://dx.doi.org/10.35381/r.k.v5i10.697

\title{
Estrategias de marketing viral y el posicionamiento de marca en el sector farmacéutico
}

Viral marketing strategies and brand positioning in the pharmaceutical sector

\author{
Karina Monserrath Siguenza-Peñafiel \\ karina.siguenza@psg.ucacue.ed.ec \\ Universidad Católica de Cuenca, Cuenca \\ Ecuador \\ https://orcid.org/0000-0002-4102-5226 \\ Juan Carlos Erazo-Álvarez \\ jcerazo@ucacue.edu.ec \\ Universidad Católica de Cuenca, Cuenca \\ Ecuador \\ https://orcid.org/0000-0001-6480-2270 \\ Cecilia Ivonne Narváez-Zurita \\ inarvaez@ucacue.edu.ec \\ Universidad Católica de Cuenca, Cuenca \\ Ecuador \\ https://orcid.org/0000-0002-7437-9880
}

Recibido: 19 de marzo de 2020

Revisado: 14 de abril de 2020

Aprobado: 07 de mayo de 2020

Publicado: 19 de mayo de 2020

\section{RESUMEN}

La marca es la percepción más favorable para incidir en el momento de la adquisición en la mente de los clientes, en donde se crea un nexo entre el consumidor y la organización. Por lo tanto, Cadena de farmacias Suiza ubicada en la provincia del Cañar, en la cuidad de Azogues-Ecuador, es una empresa dedicada a la venta de productos farmacéuticos. La presente investigación tiene como objetivo desarrollar estrategias de marketing viral y de posicionamiento de marca en el sector farmacéutico. La metodología aplicada es de tipo descriptivo, transversal con un enfoque mixto utilizando el método inductivo-deductivo. Se encontró la carecía de estrategias acorde a la nueva era tecnología en donde se tiene un consumidor digital y siempre al día en la 


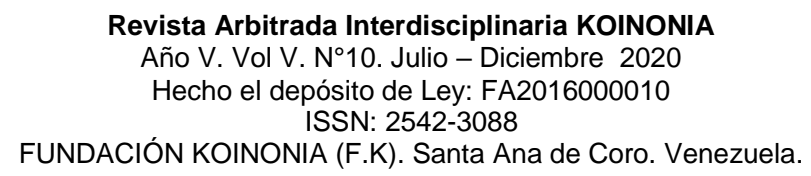

Karina Monserrath Siguenza-Peñafiel; Juan Carlos Erazo-Álvarez; Cecilia Ivonne Narváez-Zurita

era tecnología con una tendencia de compra cada vez más virtual. Se concluye que el aporte de las estrategias de marketing viral es fundamental para mejorar el posicionamiento.

Descriptores: Marketing; publicidad; administración; operación administrativa. (Palabras tomadas del Tesauro UNESCO).

\begin{abstract}
The brand is the most favorable perception to influence the moment of acquisition in the minds of customers, where a link is created between the consumer and the organization. Therefore, the Swiss pharmacy chain located in the Cañar province, in Azogues cityEcuador, is a company dedicated to the sale of pharmaceutical products. This research aims to develop viral marketing and brand positioning strategies in the pharmaceutical sector. The applied methodology is descriptive, transversal with a mixed-methods approach using the inductive-deductive method. The lack of strategies was found according to the new technology era regarding a digital consumer and always up to date in technology with an increasingly virtual buying trend. It is concluded that the contribution of viral marketing strategies is essential to improve positioning.
\end{abstract}

Descriptors: Marketing; advertising; administration; management operations. (Words taken from the UNESCO Thesaurus).

\title{
INTRODUCCIÓN
}

En Ecuador hoy en día con un mercado cada vez más competitivo, en donde el consumidor no solo busca precios económicos sino más bien el valor agregado que se les puede dar a los mismos, se determina que la marca es la percepción más favorable para incidir en el momento de la adquisición en la mente de los clientes, en donde se crea un nexo entre el consumidor y la organización. Por lo que el posicionamiento de una marca le permite al consumidor identificarse y apoderarse de ella. Del mismo modo, por medio de esta se crean semejanzas con un conjunto de personas con iguales similitudes y ponen distancia con el conjunto de personas que consideran diferentes (Ballesteros, 2016). 


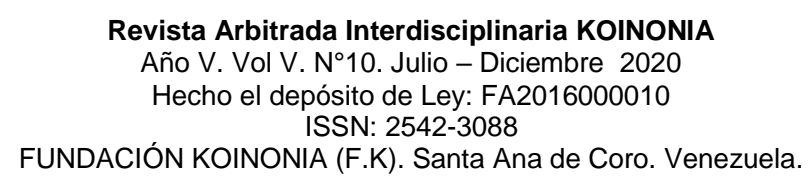

Karina Monserrath Siguenza-Peñafiel; Juan Carlos Erazo-Álvarez; Cecilia Ivonne Narváez-Zurita

De la misma manera, desde la década de los noventa hasta la actualidad, se observa que la marca se ha convertido en uno de los componentes más importantes para pequeñas y grandes empresas, puesto que, el consumidor por un slogan, una imagen, una palabra, o un símbolo relaciona y se conecta íntimamente con el producto o el servicio que las organizaciones ofrecen. Un caso muy particular son los "aros dorados" de McDonalds, los cuales son reconocidos en cualquier parte del mundo, es ahí donde se observa la importancia de tener una marca fuerte, debido a que, a pesar de que existan varios restaurantes en todas las ciudades del mundo, se caracterizan por brindar un servicio rápido y oportuno.

De esta manera la marca está constituida como uno de los elementos intangibles más transcendentales debido a que contribuyen en el proceso de diferenciación de la empresa con relación a la competencia debido a que ayuda a la organización a generar una percepción positiva en la mente del consumidor. Por tanto, este intangible debe ser gestionado de forma adecuada, puesto que tiene la capacidad de (I) aportar reputación y prestigio, (II) fidelizar al cliente, (III) generar afinidad e interés emocional entre un conjunto de personas con semejanzas, (IV) dificultad para ser imitados (Aguerrebere, 2014). Hoy en día por medio de la tecnología se puede lograr la captación de clientes potenciales el incremento de ventas y la optimización de gastos mediante una vía de comunicación innovadora y efectiva sin disminuir la calidad de servicio hacia los clientes. (Aguado \& García, 2009) afirman;

El marketing viral involucra a sus destinatarios, seduce, evoluciona en manos de los consumidores, que lo hacen creíble para otros consumidores. Una campaña de marketing no puede llamarse viral antes de haberse lanzado. "Viral" es un adjetivo que una campaña se gana cuando los consumidores la hacen suya, participan, la comentan y la amplifican. Su valor crece con el uso. El marketing viral se refuerza cuando se multiplica, y esto constituye una excelente barrera de entrada contra los competidores. Como buen virus, se alimenta de redes, sistemas, e infraestructuras ya construidas. (p.3)

Dentro de este contexto, cadena de farmacias Suiza ubicada en la provincia del Cañar, en la cuidad de Azogues-Ecuador, presente con 38 sucursales en los cantones: La 


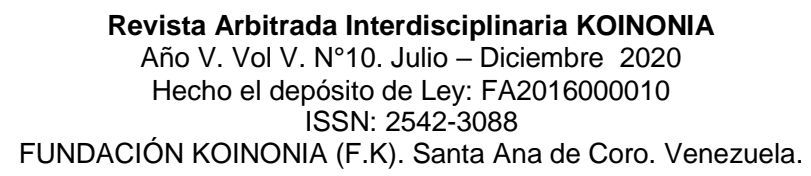

Karina Monserrath Siguenza-Peñafiel; Juan Carlos Erazo-Álvarez; Cecilia Ivonne Narváez-Zurita troncal, Suscal, El tambo, Cañar, Biblián y Azogues, con una trayectoria de 40 años de servicio a la comunidad, es una empresa que se dedica a la venta de productos farmacéuticos caracterizados por el servicio a sus consumidores y los beneficios a sus colaboradores.

El problema radica en la ausencia de estrategias de marketing viral y de posicionamiento de marca, debido a que el crecimiento de la empresa es por iniciativa y empoderamiento de la gerencia, de manera empírica sin considerar que en la actualidad el mercado reacciona de manera más dinámica, en donde el consumidor no solo busca precios económicos sino el valor agregado que se les puede dar a los mismos.

La creación de una marca es un proceso integrativo, que busca construir marcas poderosas; es decir, marcas ampliamente conocidas, asociadas a elementos positivos, deseadas y compradas por una base amplia de consumidores. Esto incluye la definición de la identidad o imagen que se quiere tener en un mercado, su diseño gráfico y la puesta en escena de la marca frente a determinados públicos, de manera que tome relevancia y, además, rentabilidad a través de todos los procesos de compra y recompra de la misma. (Hoyos - Ballesteros, 2016, p.1)

El objetivo del presente estudio es desarrollar estrategias de marketing viral y de posicionamiento de marca lo que le permite al consumidor identificarse y apoderarse de ella. El término valor de marca, "nace a mediados de la década del ochenta, un momento en el que los mundos de las finanzas y del marketing tomaban conciencia del enorme valor económico de las marcas, (...) un eslogan que agrupa conceptos distintos" (Batey, 2013, p 20).

\section{Referencial teórico}

\section{El marketing como herramienta digital}

La creciente tendencia por las tecnologías de la información y comunicación e internet ha desarrollado una demanda de información continua por parte de los usuarios en donde se ofrece nuevas oportunidades por medio del marketing digital. Internet brinda un beneficio de conexión en tiempo real para dichos usuarios por medio de una 


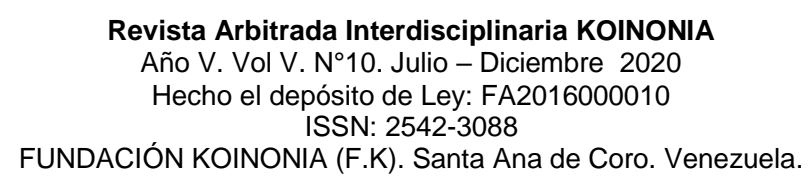

Karina Monserrath Siguenza-Peñafiel; Juan Carlos Erazo-Álvarez; Cecilia Ivonne Narváez-Zurita

comunicación directa y personalizada, sin la necesidad de la presencia del usuario, por medio de esta se puede resolver cualquier duda o inquietud que se le presente, por este motivo los clientes se sienten más satisfechos y fidelizados con la empresa (Hernández-Díaz, 2016).

Una estrategia de comunicación publicitaria por medio de medios digitales tiene como finalidad llegar al usuario el mismo que tiene un papel protagónico hoy en día, puesto que da como resultado la utilización de una herramienta gratuita que es el boca en boca electrónico (Electonic Word of Mouth) se llama así al WOM en línea definido por cualquier comentario positivo o negativo que una persona tenga de una marca 0 empresa a través de la plataforma de internet; sin embargo, carece un poco de credibilidad debido a que los usuarios pueden utilizar el anonimato para dar opiniones de los servicios o productos de la marca que se promociona (Paús \& Macchia, 2014).

Dentro de este contexto, existe otra estrategia publicitaria como es el Search Engine Marketing o PPC antes llamado pago por clic es el proceso de utilización de sitios de búsqueda en la web, el cual deber ser pagado para promover de una manera privilegiada y rápida que aparezca primero en los buscadores. De la misma manera, (Hernández-Díaz, 2016) en su artículo cientifico denominado El Marketing Digital en la clínica dental determina que la publicidad en internet es bastante mas barata que la publicidad tradicional y los anuncios deben ir orientados hacia lo que busca el usuario; como tambien además de la inversion influyen otros aspectos como la calidad y redacción del anuncio, por lo que se tienen que cumplir los siguientes paramentos como rapidez, diseño y optimización para que el anuncio sea eficiente y oportuno.

\section{El marketing viral}

Es una estrategia de publicidad que se realiza mediante canales online que aprovecha las redes sociales y otros medios para aumentar el reconocimiento de su marca o servicio, por medio de mensajes, publicaciones, historias en tiempo real. Además, de tener un mínimo costo de inversión abarcando un crecimiento exponencial de los usuarios que pueden ser distribuidos en diferentes lugares a nivel mundial. Por otro 


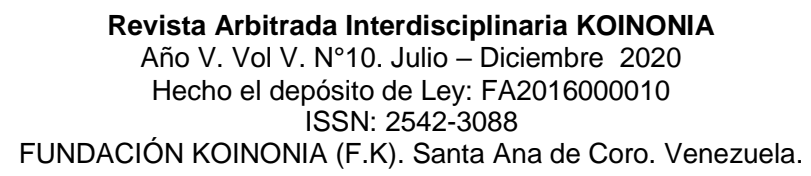

Karina Monserrath Siguenza-Peñafiel; Juan Carlos Erazo-Álvarez; Cecilia Ivonne Narváez-Zurita lado, es una herramienta para la interacción virtual del usuario y retroalimentación de sus necesidades, inquietudes y recomendaciones a cerca del servicio que la empresa ofrece (Trelles-Méndez, Erazo-Álvarez, \& Narváez-Zurita, 2019).

Las organizaciones utilizan el marketing viral con el propósito de tener una marca fuerte comúnmente llamado reconocimiento de marca, a más de fidelizar a los consumidores en donde se logra una estrecha comunicación con sus potenciales clientes. No por eso, significa que la calidad de servicio debe ser diferente o ineficiente el reto está en lograr un servicio exactamente igual tanto en el punto de venta como a través de los medios electrónicos para poder ser diferenciados y reconocidos de la competencia (CarpioMaraza, Hancco-Gomez, Cutipa-Limache, \& Flores-Maman, 2019).

Las redes sociales se han convertido en protagonistas en la vida del ser humano, desde una corta edad las personas se vuelven dependientes de la tecnología, inclusive la población que conforma la tercera edad son personas altamente activas en el mundo online, no es un obstáculo no haber nacido en la era de las tecnologías de la información debido a la cantidad de influencia de personas, les motiva para al igual que todos tener una red social para informarse, aprender, motivarse o simplemente comunicarse. Existen algunas ventajas y desventajas del uso de las redes sociales como son:

Ventajas

1. La comunicación inmediata de parte de los usuarios con la empresa

2. Con poca inversión se alcanza una gran cantidad de personas

3. No tiene costo la suscripción a las redes sociales

4. Se puede definir y segmentar el público objetivo para poder lograr mejores resultados

5. La información se propaga de manera rápida en tiempo real a todos los usuarios que estén conectados

6. Se pude atraer visualmente a los usuarios con formatos e imágenes dinámicas y divertidas 


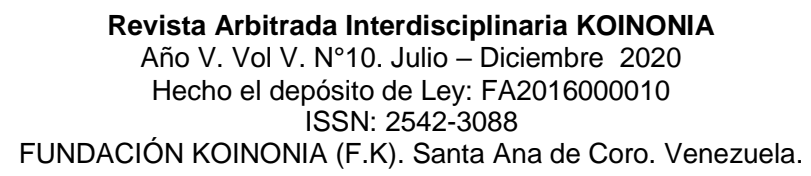

Karina Monserrath Siguenza-Peñafiel; Juan Carlos Erazo-Álvarez; Cecilia Ivonne Narváez-Zurita

Desventajas

1. Los usuarios perciben desconfianza de la información online

2. Se genera mayor competitividad por parte de las empresas afines a la misma actividad comercial

3. Cada persona asume a su manera la información que se proyecta

4. El uso inadecuado de la marca o de la empresa

5. Se exponen a críticas de personas pagadas por la competencia, fomentando comentarios negativos

6. Dificultad para la formulación de mensajes que motiven a compartir y generar una recomendación clic a clic

\section{El marketing de servicios}

Un servicio no se puede almacenar, su producción puede o no estar asociada a un artículo tangible, son las diversas actividades que la organización ejecuta para satisfacer las necesidades del cliente, el cual le permita una interacción con el mismo. El servicio es un bien intangible que posee heterogeneidad busca crear oportunidades de mercado para captar nuevos clientes, en donde se tiene como pilar fundamental presentar un servicio distinto y específico para cada persona, que permita diferenciarse de los demás (Vega, Paz, \& Basantes, 2014), por su parte (Estrada, 1996) indica que para brindar un buen servicio es muy importante la comunicación lo que implica factores relevantes como:

1. El lenguaje que significa el comportamiento cotidiano de las personas lo que incluye al lenguaje corporal. La forma en que la que un colaborador de la empresa (vendedor) trata a un usuario su forma de hablar, su terminología, la posición de su cuerpo, sus manos.

2. La sensopercepción que engloba la habilidad de percatarse y descubrir señales acerca de los requerimientos que transmite o denota el cliente a utilizar el servicio. 


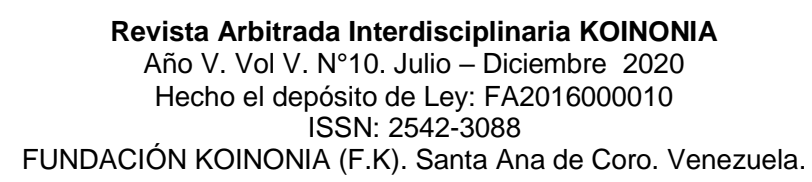

Karina Monserrath Siguenza-Peñafiel; Juan Carlos Erazo-Álvarez; Cecilia Ivonne Narváez-Zurita

3. La proyección psicológica que es la seguridad que se trasmite del servicio que se ofrece a más de la retroinformación en donde el colaborador de la empresa o servicio debe estar capacitado para escuchar y responder las inquietudes o requerimientos del cliente. Como también entender sus requerimientos y recomendarle las mejores opciones para sus necesidades

4. La motivación en donde el consumidor puede ser motivado por muchos factores para incentivar a la compra, puede ser que sea motivado por promociones, descuentos o especiales del día, lo que le motive a adquirir un producto que ni siquiera estaba necesitando

En la actualidad, las empresas a más de vender el producto deben ofertar una prestación complementaria para tener un beneficio que conlleve a la fidelización de los consumidores por medio de un feedback. Como también, aprovechar la tecnología para que lo convierta en un beneficio para llegar al consumidor de manera rápida, sencilla y oportuna; adicional a esto, se puede llegar de una forma masiva a todos los clientes ya existen y futuros compradores (Ávila-Sacoto, Erazo-Álvarez, Narváez-Zurita, \& ErazoÁlvarez, 2019).

\section{Posicionamiento de marca}

El posicionamiento se construye por medio de campañas comunicacionales a través de los medios convencionales como son la televisión, la radio y últimamente las redes sociales son el medio más utilizado; el posicionamiento es crear un valor agregado a los productos y hacer extensivo a través de los medios de comunicación a sus clientes y colaboradores. Esto implica que se debe conseguir alianzas estratégicas con los proveedores, en donde se debe conseguir promociones puntuales o descuentos significativos, los cuales sirvan como un ancla para captar nuevos clientes y mantener la fidelidad de los ya existentes.

Según (Silva, González, Martínez, Giraldo, \& Juliao, 2014), se tiene dos tipos de posicionamientos: El primero, el posicionamiento deseado que es el lugar que la empresa espera que la marca, producto o servicio ocupe en la mente del consumidor. 


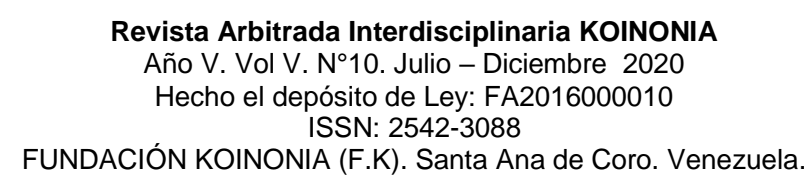

Karina Monserrath Siguenza-Peñafiel; Juan Carlos Erazo-Álvarez; Cecilia Ivonne Narváez-Zurita

En el caso de que la empresa desee vender "economía", se debe generar ese ambiente de ofertas y descuentos en donde se crea una experiencia ahorro. No obstante, en el caso que la empresa desee vender "exclusividad", se debe generar un lugar de precios altos con calidades inigualables. El segundo, el posicionamiento percibido es la percepción que el consumidor tiene de la marca, producto o servicio, por ende, es el más importante, debido a que, si la empresa pretende ser percibida con los mejores precios y las grandes promociones, no obstante, el cliente no lo percibe así es ahí donde se debe crear estrategias para que la empresa logro transmitir a los clientes la experiencia que deseen comunicar correctamente.

\section{Estrategias para el marketing farmacéutico}

Las estrategias de marketing tienen una visión transaccional dirigido a la promoción de productos o servicios. En este sentido, la marca es entendida como un símbolo o una palabra que identifica un activo económico frente a la competencia. Hoy en día una estrategia competitiva es lo que la gente piensa de la marca de la empresa; la combinación de los beneficios con relación al precio es lo que conlleva a la estrategia más importante para el posicionamiento de los productos o servicios, en este sentido, Kotler y Armstrong (2013), indican que:

1. La primera es más por más: Es cuando se proporciona un producto exclusivo y se va a cobrar más alto el precio para cubrir con los costos altos que esto implica. Además de ofrecer el prestigió al comprador lo que simboliza un estatus y estilo de vida elevado. Sin embargo, esta estrategia esta propensa a que los imitadores ofrezcan lo mismo de la misma calidad, pero a menor precio. Adicional a esto, si el país enfrentara una crisis económica donde golpea a todos, esta estrategia es afectada debido a que las personas tratan de minimizar los gastos.

2. La segunda es más por lo mismo: Las organizaciones pueden arremeter la estrategia de la competencia de más por más por medio de una marca que 


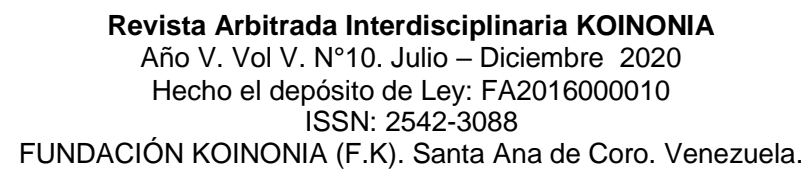

Karina Monserrath Siguenza-Peñafiel; Juan Carlos Erazo-Álvarez; Cecilia Ivonne Narváez-Zurita

brinde calidad a menor precio. Es cuando se ofrece la misma calidad a un mismo precio, el cual comparado con la competencia es menor.

3. La tercera es lo mismo por menos: Ofrecer lo mismo por menos puede ser el componente más importante en la propuesta de valor. A todas las personas les gusta se bien atendidos y encontrar en un solo lugar lo mismo, pero a menos precio.

4. La cuarta es menos por mucho menos: Se refiere a compensar exigencias de calidad baja a un precio inferior, puesto que existe un mercado para el cual no le importa la calidad sino solo el precio más bajo.

5. La quinta es más por lo menos: muchas empresas dicen hacer esto, pero solo es posible a corto plazo para ganar posicionamiento. Pero a largo plazo a las empresas les resulta difícil ya que dar más por lo usual cuesta más y no se puede llevar a cabo el "menos".

Dentro del este contexto existen un proceso de compra el cual consta de 5 fases las cuales son:

1. Identificar las falencias de los usuarios: Los cuales pueden ser provocados por estímulos internos y externos; en esta etapa se debe analizar al consumidor para indagar sus necesidades y la motivación de como dirigir al consumidor a un producto.

2. Búsqueda de información: Es el momento el cual un consumidor que está motivado por algún factor como la necesidad de adquisición indaga por medio de recomendaciones de familiares o amigos como también de fuentes como es el caso de la publicidad, redes sociales o directamente en el punto de compra del producto, es por ello que cuando el cliente se acerca por información el personal tiene que estar capacitado para poder dar la información necesaria y enganchar a los posibles compradores.

3. Evaluación de alternativas: Es el momento en donde con la información del servicio o producto que obtiene el cliente analiza posibles opciones para adquirir 


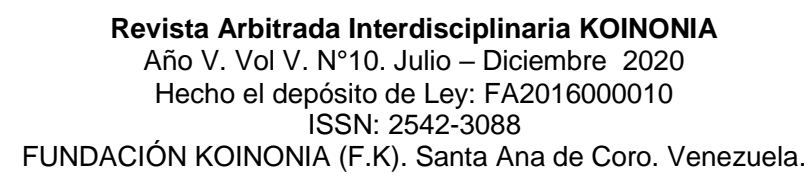

Karina Monserrath Siguenza-Peñafiel; Juan Carlos Erazo-Álvarez; Cecilia Ivonne Narváez-Zurita

la que más le favorece lo cual es necesario ofrecer diferentes opciones para poder influir en la toma de decisiones

4. Decisión de compra: Lo engloba dos factores que influyen en el momento cero como es el comentario que tiene otra persona acerca de aspectos que no eran relevantes influyendo en la toma de decisiones del cliente y creando necesidades con situaciones imprevistas para impulsar a la compra

5. Comportamiento que motive a la recompra: La cual depende de la satisfacción del cliente si el servicio cumple con todas las expectativas a la vez que es fundamental superar las mismas para poder incentivar a la recomendación con su círculo familiar.

\section{MÉTODO}

La presente investigación es de tipo no experimental debido a que no existe ninguna manipulación de las variables de estudio mediante el cual se analizan en su entorno natural. El enfoque de la investigación es de carácter mixto "en el cual se combinan en una misma etapa o fase de investigación, tanto métodos cuantitativos, como cualitativos" (Pereira-Pérez, 2011, p.19). La metodología que se aplico es de tipo descriptivo transversal, la cual se encarga de observar y describir un fenómeno, Hernández, Fernández, \& Baptista (2014) sostienen:

Con los estudios descriptivos se busca especificar las propiedades, las características y los perfiles de personas, grupos, comunidades, procesos, objetos o cualquier otro fenómeno que se someta a un análisis. Es decir, únicamente pretenden medir o recoger información de manera independiente o conjunta sobre los conceptos o las variables a las que se refieren, esto es, su objetivo no es indicar cómo se relacionan éstas. (p.92)

El estudio tuvo un alcance descriptivo-explicativo debido a que se investigaron varias teorías en base a las variables de la investigación; la metodología aplicada es de tipo transversal la cual se encarga de observar y describir un fenómeno en un solo periodo de tiempo. Para este estudio se utilizó el método histórico-lógico el cual estudia las teorías, leyes y desarrollo de fenómenos de manera cronológica en el presente 


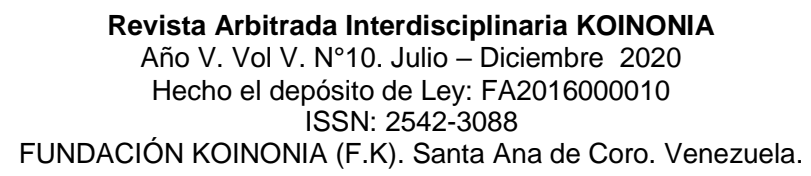

Karina Monserrath Siguenza-Peñafiel; Juan Carlos Erazo-Álvarez; Cecilia Ivonne Narváez-Zurita

documento para su fundamentación teórica. De la misma manera, se utilizó el método analítico- sintético que según: Rodríguez-Jiménez, \& Pérez-Jacinto (2017):

Se refiere a dos procesos intelectuales inversos que operan en unidad: el análisis y la síntesis. El análisis es un procedimiento lógico que posibilita descomponer mentalmente un todo en sus partes y (...). La síntesis es la operación inversa, que establece mentalmente la unión o combinación de las partes previamente analizadas y posibilita descubrir relaciones y características generales entre los elementos de la realidad. (p. 8)

Además, se utilizó el método deductivo-inductivo que sirvió para la construcción de conocimientos leyes y teoremas generales de estrategias de marketing para sacar conclusiones particulares, en cambio el método inductivo se realizó a partir de la observación y de definiciones de cada concepto para llegar a conclusiones generales. Finalmente, las técnicas utilizadas fueron la observación y la encuesta para recabar información necesaria e indispensable de las variables cuyo instrumento fue el cuestionario (Erazo-Álvarez \& Narváez-Zurita, 2020).

\section{Universo de estudio y tratamiento muestral}

Puesto que el universo de estudio es finito en esta investigación se consideró un parámetro que es la frecuencia de compra durante un periodo determinado el cual es 31 días para la segmentación de los clientes de la cadena de farmacias suiza el universo son los 105 clientes que acuden a comprar por 4 veces durante ese lapso de tiempo establecido, con un $10 \%$ de error y $90 \%$ de confiabilidad el valor de la muestra es de 81 , siendo este resultado la cantidad de encuestas que deben ser aplicadas a los clientes. 


\section{RESULTADOS}

La estructura de la propuesta de estrategias de marketing viral se presenta a continuación en la figura 1.

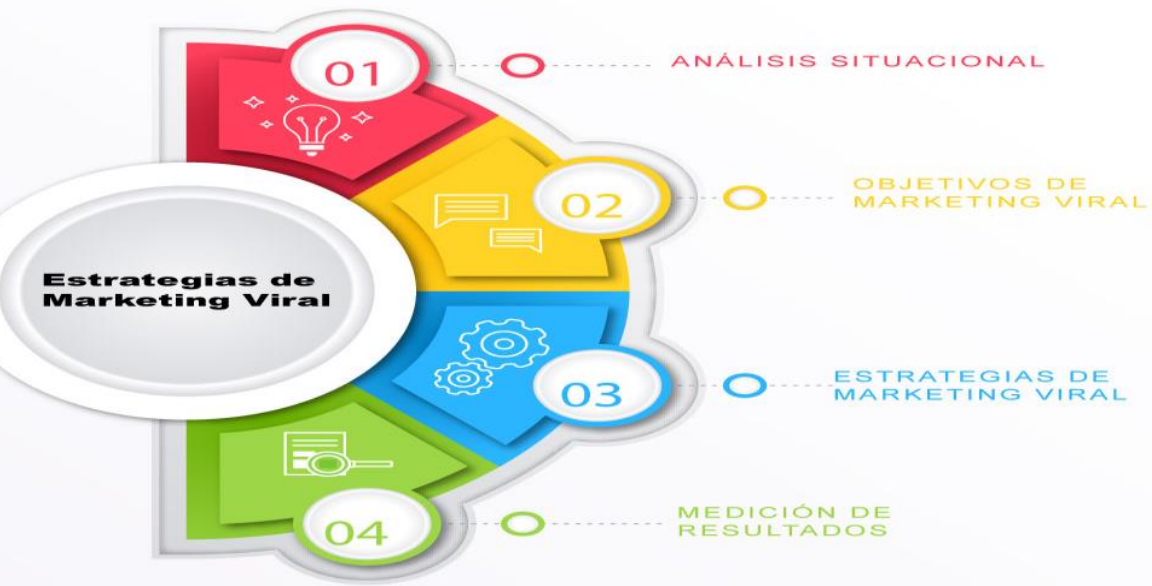

Figura 1: Estrategias de Marketing Viral. Fuente: Elaboración propia

\section{Análisis situacional de la empresa}

En base a los resultados obtenidos que se aplicaron a los clientes más frecuentes de la cadena de farmacias suiza; se establece que el $32 \%$ de encuestados son de género masculino y el $49 \%$ son de género femenino. Por otro lado, los rangos de edad que más predominaron son con el $21 \%$ la edad entre 18 a 27 años y con un $27 \%$ la edad entre 38 a 47 años. Además, de que el $60 \%$ de las personas encuestadas son de estado civil casados siendo estas las características de su mercado potencial.

Dimensión: Imagen

En esta dimensión se observa que el 39,6\% de las personas que fueron encuestadas tienen preferencia por el logotipo de la cadena de farmacias suiza el 60,4\% tienen inclinación por otras marcas.

Dimensión: Posicionamiento

En esta dimensión se observa que el 58,3\% de los encuestados tienen preferencia por cadena de farmacias suiza el $41,7 \%$ tiene favoritismo por otras farmacias. 


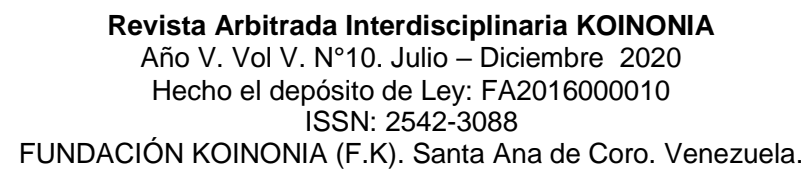

Karina Monserrath Siguenza-Peñafiel; Juan Carlos Erazo-Álvarez; Cecilia Ivonne Narváez-Zurita

Dimensión: Producto

Según esta dimensión el comportamiento del cliente considera que el 94,4\% de las personas que fueron encuestadas necesitan que una farmacia tenga variedad de productos tanto farmacéuticos como populares, en donde se puede encontrar todo en un solo lugar, Además de que el $80,6 \%$ de los encuestados consideran que son muy importante tenga precios económicos y accesibles.

Dimensión: Promociones

De acuerdo con esta variable las personas encuestadas consideran que las promociones y sorteos al momento de realizar una compra incidan al cliente un 64,8\%, de la misma manera un $94,4 \%$ de los encuestados están de acuerdo con intensificar por medio de redes sociales las promociones y sorteos que realice la farmacia, además de que un $72,2 \%$ opina que se debe implementar la venta mediante una proforma web. Dentro de este contexto también un $57,7 \%$ está de acuerdo con recibir notificaciones personales de las promociones mediante un mensaje directo a los clientes, también un $41.7 \%$ de recibir consejos de belleza y de salud en todas las plataformas digitales.

Dimensión: Preferencias

Con un $91,7 \%$ de las personas encuestadas consideran que el servicio al cliente es lo más importante para poder tener una experiencia de compra agradable e incentivo a la recompra.

\section{Objetivos}

Aumentar las ventas por medios digitales en un $10 \%$ entre los meses comprendidos entre julio y diciembre del 2020. Utilizar las redes sociales para compartir los productos que se ofrecen además de compartir consejos de salud en donde se busca el posicionamiento de cadena de farmacias suiza en la cuidad de Azogues. 
Karina Monserrath Siguenza-Peñafiel; Juan Carlos Erazo-Álvarez; Cecilia Ivonne Narváez-Zurita

\section{Estrategias del producto}

Farmacia suiza, tiene más de 40 años en el mercado su distintivo es una mascona de forma de un gallo, la misma que en el transcurso de los años ha sido mejorada hasta que se plantea que utilice un mandil el cual representa a la profesión de un médico, y a la vez que la i sea de forma de una pastilla como representación a los productos e insumos médicos que comercializa la cadena de farmacias suiza. Por lo tanto, en la figura 2 se muestra el logotipo de farmacias suiza.
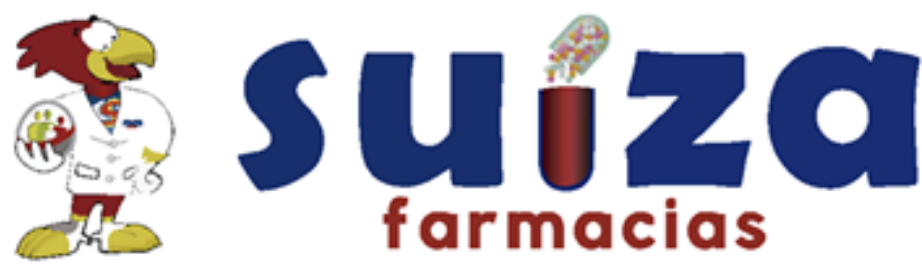

Figura 2: Logotipo de cadena de farmacias suiza. Fuente: Elaboración propia

\section{Estrategias de venta}

La empresa cuenta con 33 sucursales a nivel de la provincia del cañar y 10 están en la cuidad de azogues, sus ventas son directas es decir que el cliente tiene que acudir a cualquier punto de venta para adquirir los productos, por lo que se plantea una forma de venta online utilizando lo medios digitales, como es el caso de la figura 3 la cual se crea una fan page para que los clientes puedan relacionarse por medio de la plataforma Facebook. 
Revista Arbitrada Interdisciplinaria KOINONIA

Año V. Vol V. №10. Julio - Diciembre 2020

Hecho el depósito de Ley: FA2016000010

ISSN: 2542-3088

FUNDACIÓN KOINONIA (F.K). Santa Ana de Coro. Venezuela.

Karina Monserrath Siguenza-Peñafiel; Juan Carlos Erazo-Álvarez; Cecilia Ivonne Narváez-Zurita

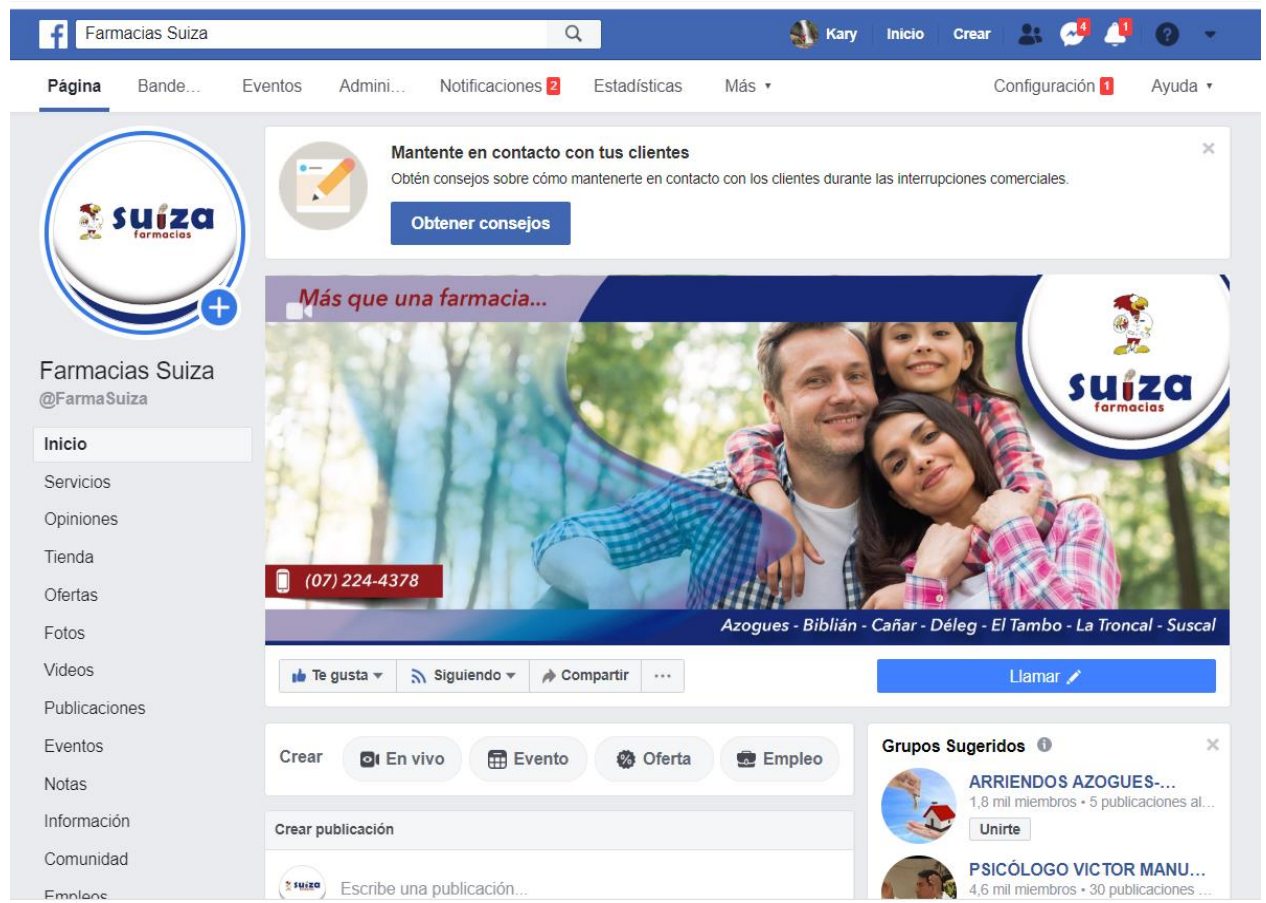

Figura 3: Fan page de Cadena de Farmacias Suiza. Fuente: Elaboración propia

Por otro lado, la fan page se utiliza para que el cliente pueda conocer los productos, precios y promociones que tiene cada semana cada de farmacias suiza, debido a que todas las semanas tienen 6 productos que están en promoción.

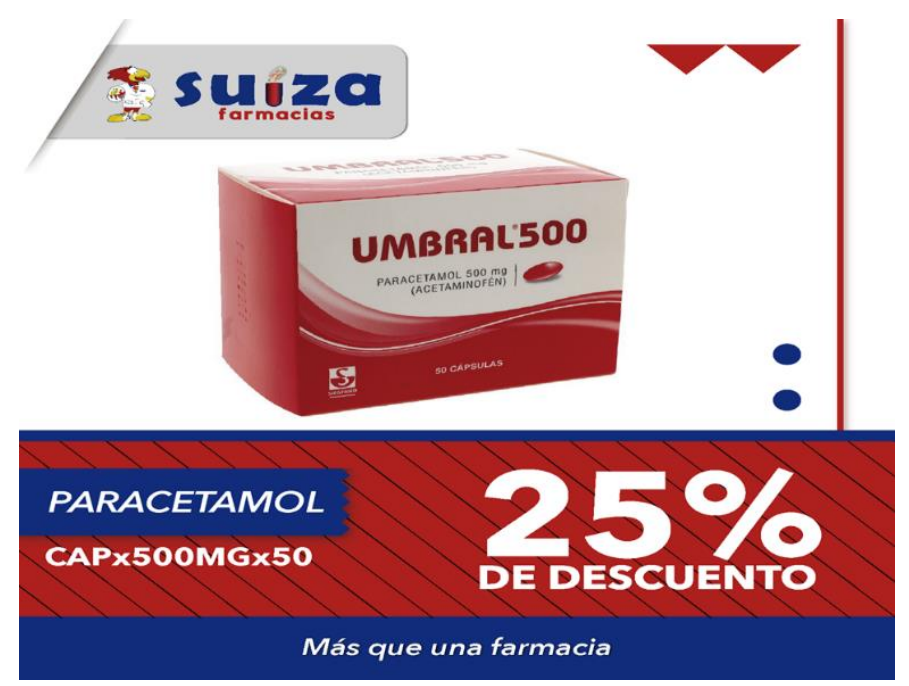

Figura 4: Promociones de Cadena de Farmacias Suiza. Fuente: Elaboración propia 


\section{Revista Arbitrada Interdisciplinaria KOINONIA \\ Año V. Vol V. №10. Julio - Diciembre 2020 \\ Hecho el depósito de Ley: FA2016000010 \\ ISSN: 2542-3088 \\ FUNDACIÓN KOINONIA (F.K). Santa Ana de Coro. Venezuela.}

Karina Monserrath Siguenza-Peñafiel; Juan Carlos Erazo-Álvarez; Cecilia Ivonne Narváez-Zurita

Siguiendo esta línea, se presenta una página web como se observa en la figura 5 en donde los clientes puedan comprar en línea cualquier producto que oferta cadena de farmacias suiza, además de conocer la historia, sus colaboradores, ubicación de cada sucursal, la misión la visión y los valores corporativos de la empresa, además que se plantea que la forma de pago sea mediante tarjeta de crédito o trasferencias bancarias de esta manera se puede satisfacer las necesidades de los clientes que hoy en día ya no utilizan el dinero en efectivo.
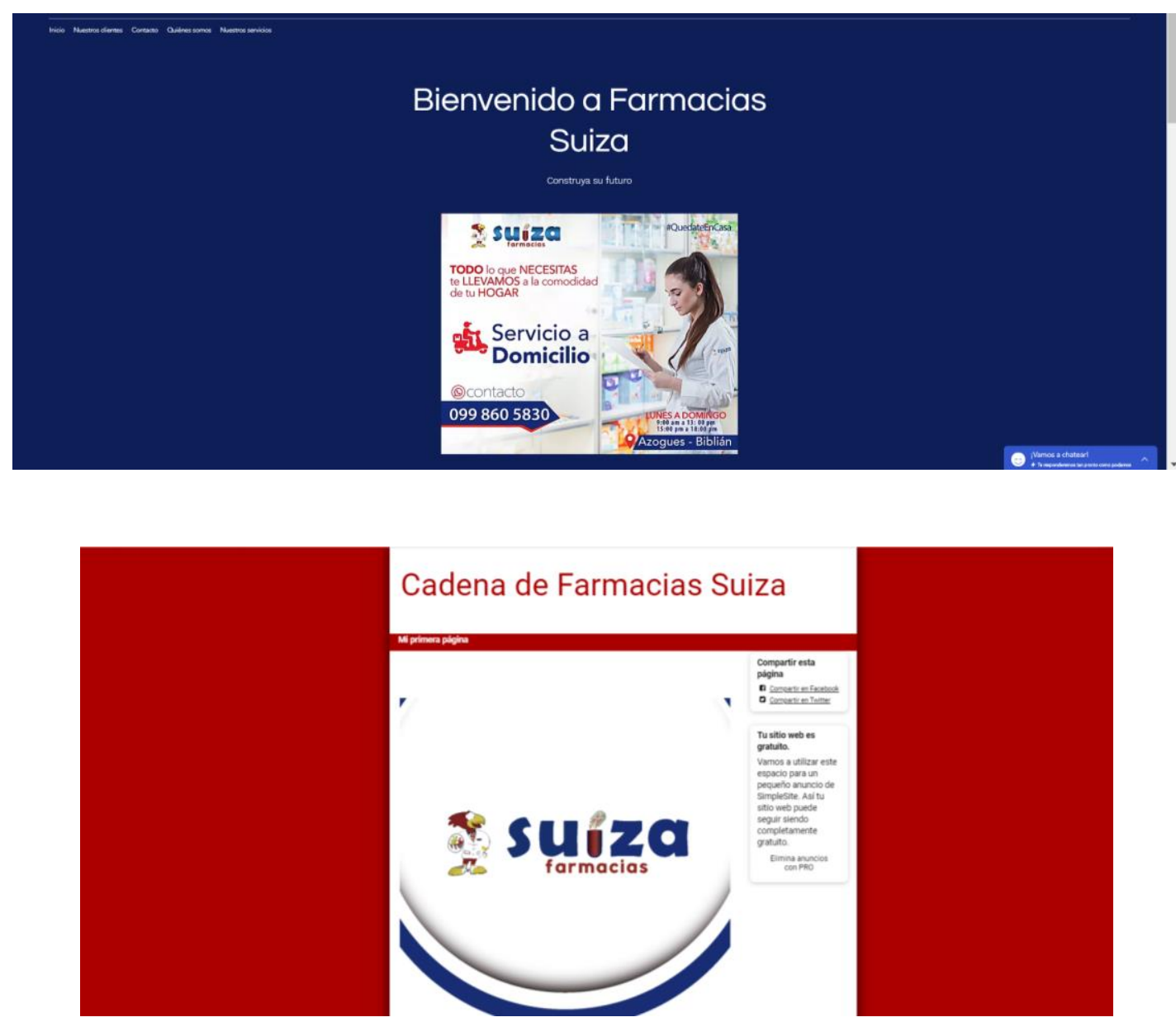

Figura 5: Página web de Cadena de Farmacias Suiza. Fuente: Elaboración propia 


\section{Estrategias De Comunicación}

El objetivo principal de esta estrategia es utilizar los medios digitales como son las redes sociales, y otras aplicaciones que brinda el internet para mantener informados a los clientes de cadena de farmacias suiza, de la misma manera se pretende fomentar la comunicación mediante los mensajes en línea para solventar cualquier duda, inquietud o requerimiento que pueda tener el usuario. Como se observa en la figura 8 , se comunica a los clientes el horario de atención y números de contacto para facilitar el pedido de los productos a domicilio.

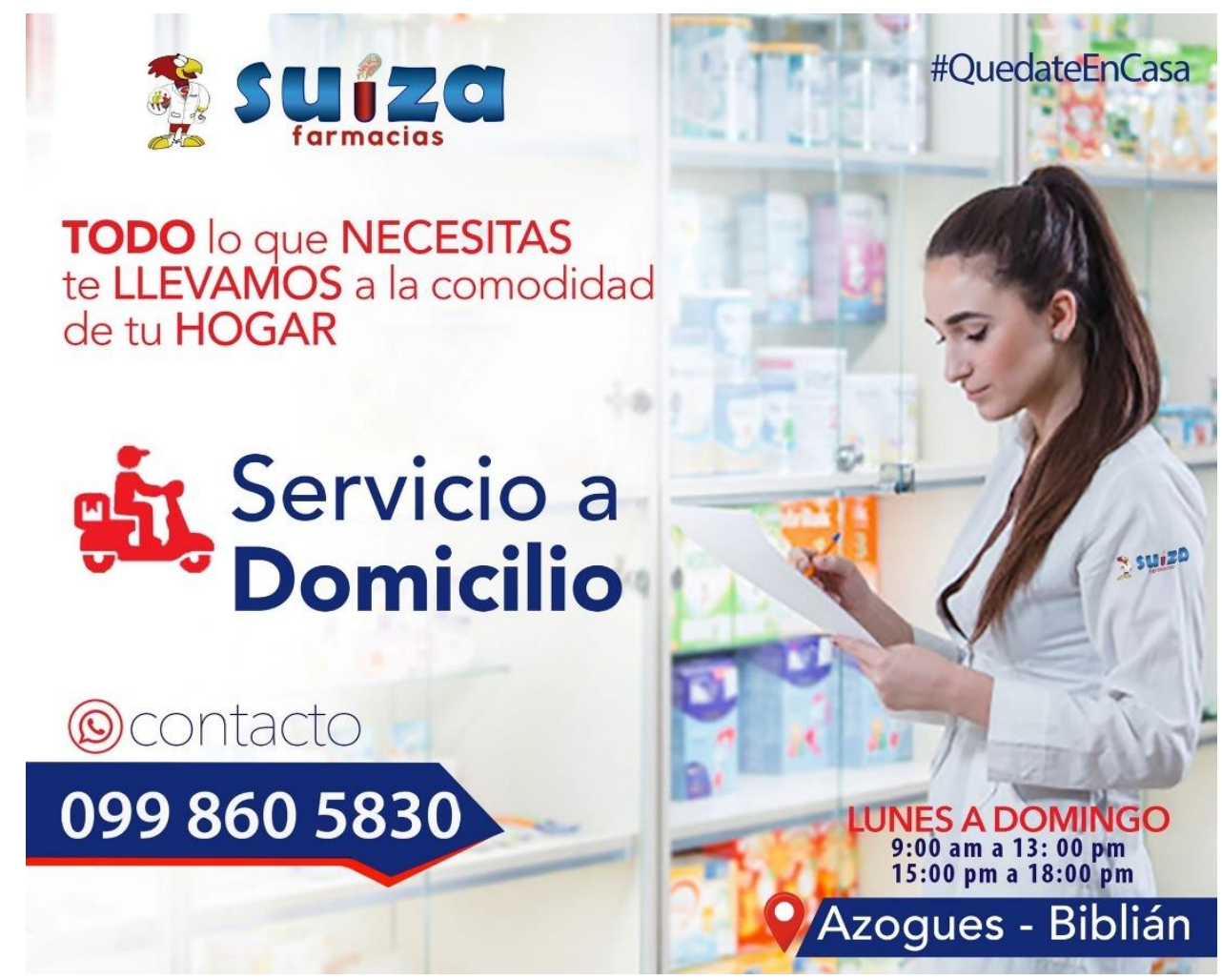

Figura 6: Publicación de horarios de atención de Cadena de Farmacias Suiza. Fuente: Elaboración propia

Dentro de este contexto, además de comunicar horarios de atención, promociones, productos o descuentos se desea transmitir al cliente frases motivacionales en donde pueda ver a farmacias suiza más que una farmacia como es su slogan sino como una 
Karina Monserrath Siguenza-Peñafiel; Juan Carlos Erazo-Álvarez; Cecilia Ivonne Narváez-Zurita empresa que a más de su salud, se preocupa por su bienestar emocional y su integridad. Como se muestra en la Figura 7 y en la Figura 8.

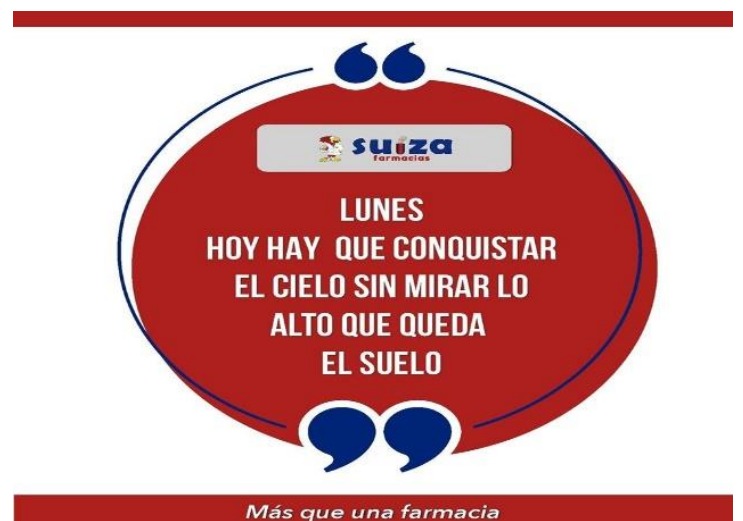

Figura 7: Frases motivacionales. Fuente: Elaboración propia

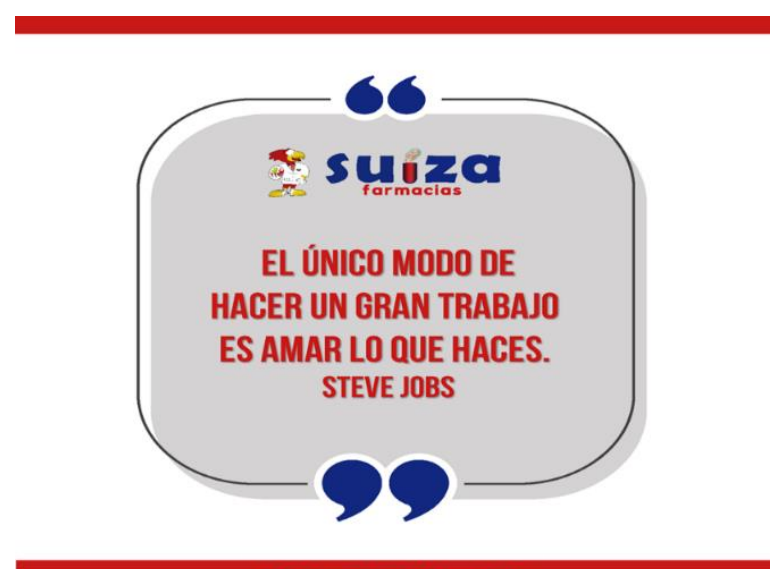

Figura 8: Frases motivacionales. Fuente: Elaboración propia

\section{Estrategias de servicio al cliente}

La finalidad de esta estrategia es fomentar en los colaboradores de cadena de farmacias suiza buenas prácticas de cortesía hacia los clientes, el objetivo principal es que sea una forma de atención estándar y unificada en todas las sucursales motivo por 


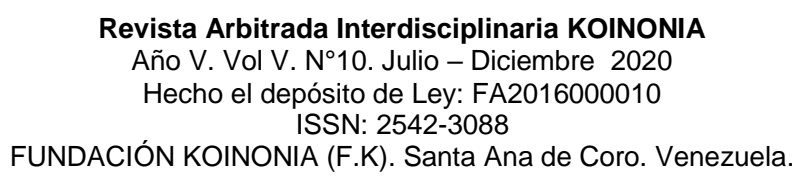

Karina Monserrath Siguenza-Peñafiel; Juan Carlos Erazo-Álvarez; Cecilia Ivonne Narváez-Zurita

el cual se desarrolla un manual de servicio al cliente como se observa en la siguiente tabla.

\section{Tabla 1}

Manual de Servicio al cliente

\section{Manual de servicio al cliente para todo el personal de Farmacias Suiza Impacta \\ Guía de Servicio \\ en}

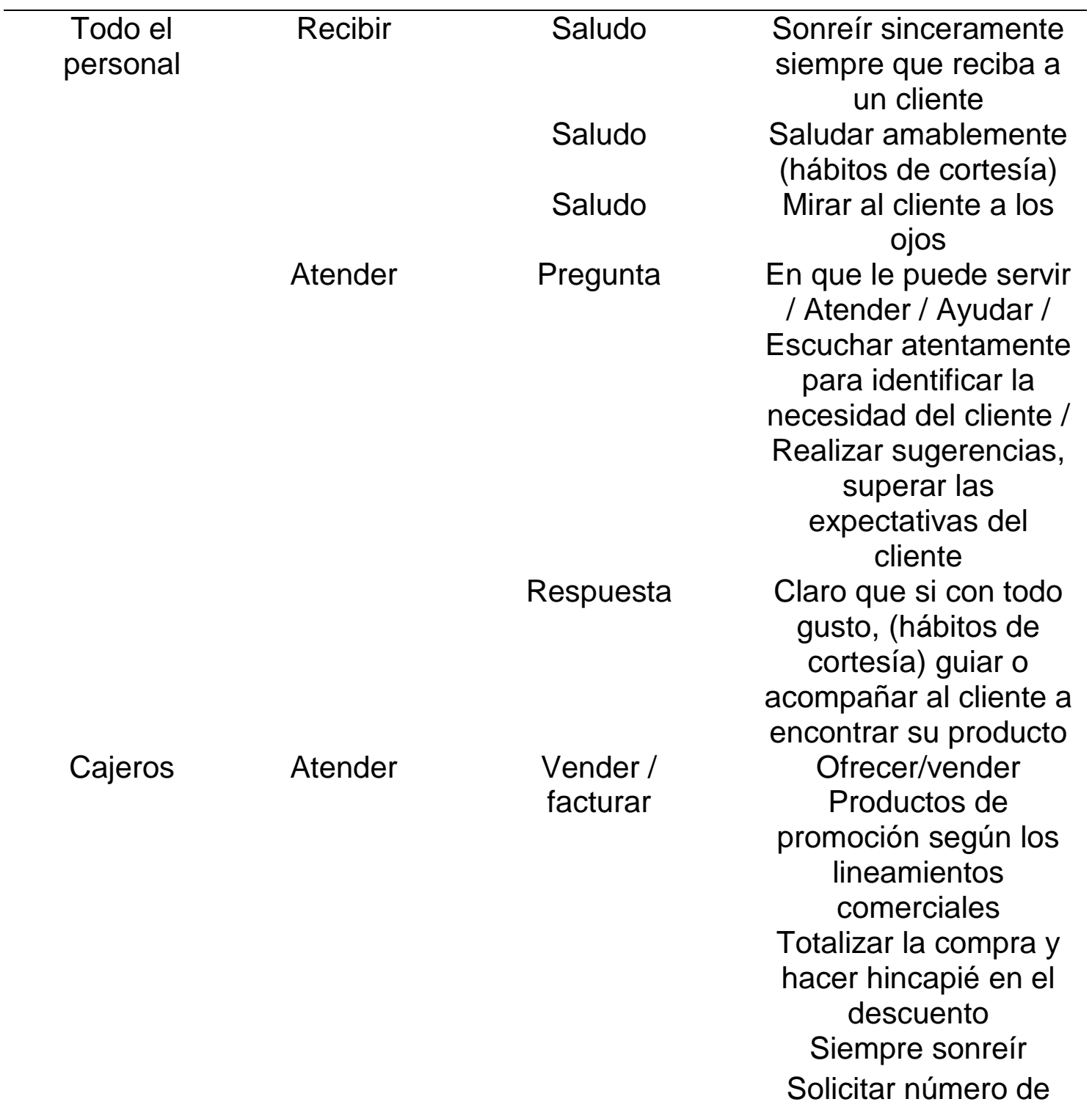


Karina Monserrath Siguenza-Peñafiel; Juan Carlos Erazo-Álvarez; Cecilia Ivonne Narváez-Zurita

Despedir

Todo el personal
Lenguaje

gestual y prohibiciones

Prohibiciones

Prohibiciones

Cerrar la orden

Prohibiciones


Karina Monserrath Siguenza-Peñafiel; Juan Carlos Erazo-Álvarez; Cecilia Ivonne Narváez-Zurita

\section{Tabla 2}

Guía de control y supervisión

Guía de control y supervisión del jefe de canal

\begin{tabular}{|c|c|c|}
\hline \multirow[t]{7}{*}{$\begin{array}{l}\text { Jefe de } \\
\text { canal }\end{array}$} & \multirow[t]{4}{*}{ Supervisión Varios } & $\begin{array}{l}\text { Supervisión directa por jefe de canal (lista de } \\
\text { verificación de la aplicación) }\end{array}$ \\
\hline & & Exámenes de conocimiento; Clínicas de venta \\
\hline & & Comprador fantasma \\
\hline & & Video / vigilancia \\
\hline & \multirow{3}{*}{$\begin{array}{l}\text { Evaluación } \\
\text { y monitoreo }\end{array}$} & Aplicación de la guía de servicio al cliente \\
\hline & & Exhibición $3 \mathrm{~F}$ (imagen interior y exterior) \\
\hline & & $\begin{array}{l}\text { Apariencia personal (uso de uniforme, peinado, uñas, } \\
\text { maquillaje, barba, cabello) }\end{array}$ \\
\hline
\end{tabular}

\section{Medición de resultados}

La medición de resultados se basa en el incremento de ventas dentro del periodo de tiempo determinado, además de diferenciar el crecimiento mediante los puntos de ventas como de las ventas digitales; además de utilizar las métricas de cada red social que brinda cada una de las plataformas en donde se va a realizar el marketing viral. Por otro lado, se dará un seguimiento y monitoreo mensual para poder realizar campañas ya sean ATL Above The Line o BTL Below The Line para el éxito de la campaña de marketing como se observa en la Figura 9. 
Karina Monserrath Siguenza-Peñafiel; Juan Carlos Erazo-Álvarez; Cecilia Ivonne Narváez-Zurita

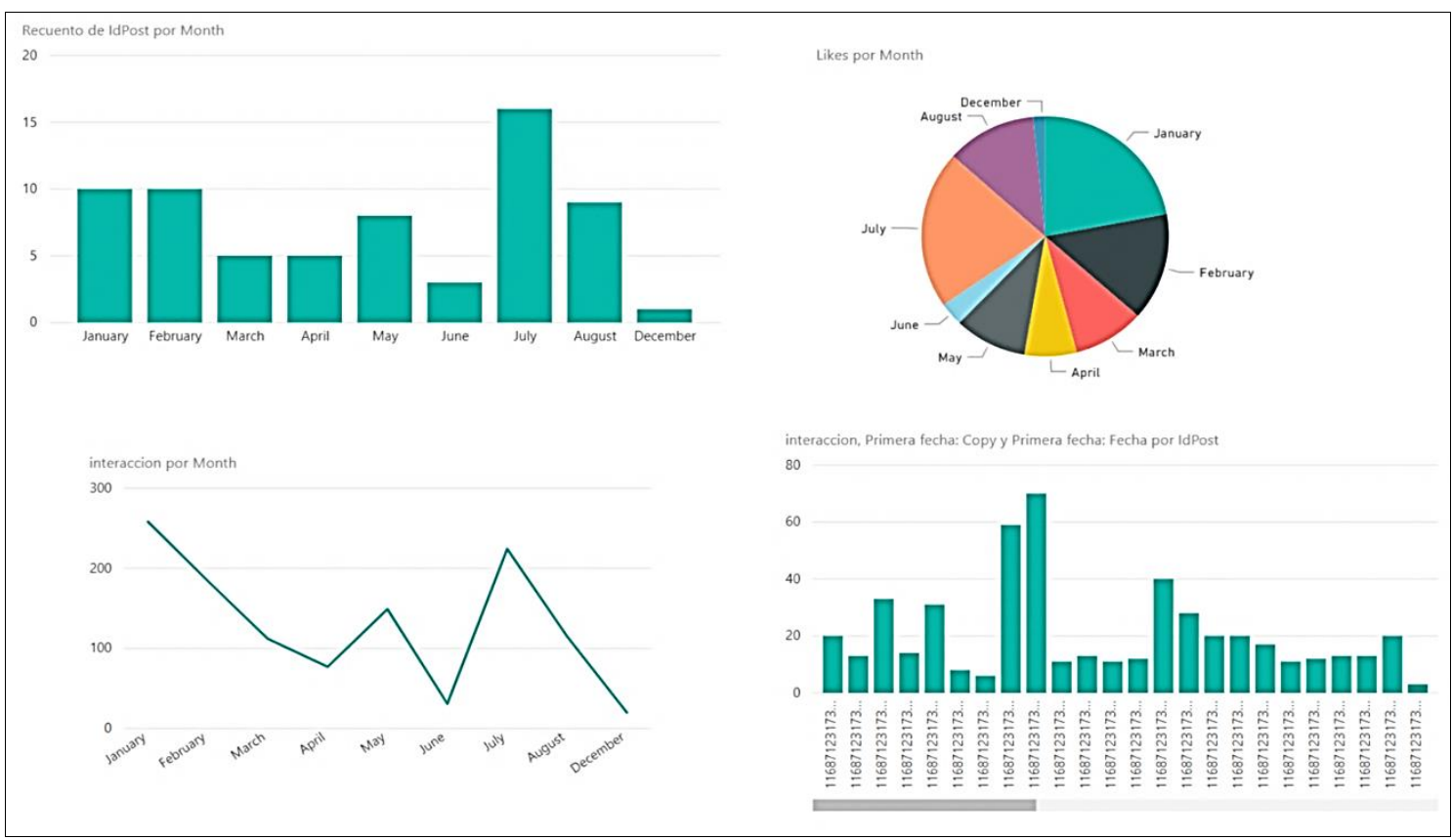

Figura 9. Indicadores que permiten la medición del impacto de las estrategias. Fuente: (Villa-Pugo, Erazo-Álvarez, Narváez-Zurita, \& Erazo-Álvarez, 2019)

\section{CONCLUSIONES}

Se concluye que en la actualidad mediante el uso del internet y las tecnologías de información no se tiene mayor restricción en cuanto a la relación entre empresa cliente, que se deben aprovechar a través de la comunicación a más de crear contenido que para el cliente sea importante y sirva como referente para solventar cualquier inquietud o duda que pueda presentarse, en donde se considera que el usuario es cambiante, curioso y actúa por impulsos inconscientes.

Cadena de farmacias suiza, tiene a lo largo de su trayectoria un dicho de mercado sin embargo no es lo suficientemente extenso, es por ello que se recomienda que se aplique las estrategias de marketing viral que se han planteado en el presente estudio, para poder tener una presencia significativa dentro del mercado y ser un referente para sus competidores. Además, se debe hacer constantemente el seguimiento respectivo y realizar mensualmente revisiones y control de los indicados que se presenta en los medios digitales. También el presente estudio le permite a la empresa tener estrategias 


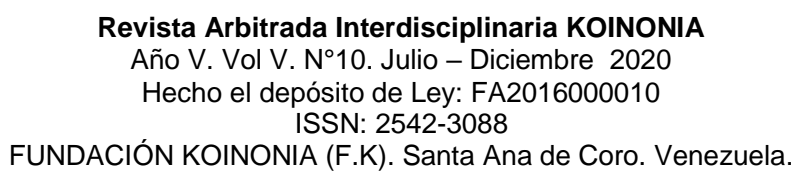

Karina Monserrath Siguenza-Peñafiel; Juan Carlos Erazo-Álvarez; Cecilia Ivonne Narváez-Zurita

de marketing fuertes e implementar en la organización una cultura dirigida hacia la comunicación y el marketing viral.

\section{FINANCIAMIENTO}

No monetario.

\section{AGRADECIMIENTO}

A la Directiva de farmacias Suiza ubicada en la provincia del Cañar, en la cuidad de Azogues-Ecuador por su valiosa colaboración y apoyo en la realización de la investigación.

\section{REFERENCIAS CONSULTADAS}

Aguado, G., \& García, A. (2009). Del word-of-mouth al Marketing Viral: aspectos claves de la comunicación a través de las redes sociales. [From word-of-mouth to Viral Marketing: key aspects of communication through social networks]. Comunicación y Hombre, 5, 41-51. https://doi.org/10.32466/eufvcyh.2009.5.112.41-51

Aguerrebere, P. M. (2014). Marca y Comunicación Empresarial. [Brand and Business Communication]. Barcelona: Editorial UOC.

Ávila-Sacoto, E., Erazo-Álvarez, J. C., Narváez-Zurita, C. I., \& Erazo-Álvarez, C. A. (2019). Estrategias de marketing digital 2.0 para la generación de ingresos en Pymes de servicios. [Digital Marketing 2.0 strategies for generating income in service SMEs]. Cienciamatria, 187-214. https://doi.org/10.35381/cm.v5i1.264

Ballesteros, R. H. (2016). Branding El arte de marcar corazones. [Branding, the art of marking hearts]. Bogota, Colombia: ECOE Ediciones.

Batey, M. (2013). El Significado de la marca. Cómo y por qué ponemos sentido a productos y servicios. [The meaning of Brand. How and why do we make sense to products and services.]. Buenos Aires, Argentina: Granica. 
Karina Monserrath Siguenza-Peñafiel; Juan Carlos Erazo-Álvarez; Cecilia Ivonne Narváez-Zurita

Carpio-Maraza, A., Hancco-Gomez, M., Cutipa-Limache, A., \& Flores-Maman, E. (2019). Estrategias del marketing viral y el posicionamiento de marca en los restaurantes turísticos de la Región de Puno. [Viral marketing strategies and brand positioning in tourist restaurants in the Puno Region]. Comuni@cción: Revista De Investigación En Comunicación Y Desarrollo, 10(1), 70-80. https://doi.org/10.33595/2226-1478.10.1.331

Erazo-Álvarez, J., \& Narváez-Zurita, C. (2020). Medición y gestión del capital intelectual en la industria del cuero - calzado en Ecuador. [Measurement and management of intellectual capital in the leather - footwear industry, in Ecuador]. Revista Arbitrada Interdisciplinaria Koinonía, 5(9), 437-467. http://dx.doi.org/10.35381/r.k.v5i9.662

Estrada, R. (1996). Creatividad en el servicio. [Creativity in service] Recuperado de: https://n9.cl/ja71n

Hernández, R., Fernández, C., \& Baptista, M. d. (2014). Metodología de la investigación. [Investigation methodology] Sexta Edción. México. D.F.: McGraw Hill.

Hernández-Díaz, F. (2016). El marketing digital en la clínica dental. [Digital marketing in the dental clinic] Recuperado de https://n9.cl/ptfy6

Hoyos - Ballesteros, R. (2016). Branding: el arte de marcar corazones. [Branding: the art of marking hearts.] Recuperado de: https://n9.cl/xjcpd

Kotler, P., \& Armstrong, G. (2012). Fundamentos del Marketing. [Marketing Fundamentals]. Pearson Education. Recuperado de https://n9.cl/axka

Paús, F., \& Macchia, L. (2014). Marketing viral en medios sociales: ¿qué contenido es más contagioso y por qué? [Viral social media marketing: which content is most contagious and why?] Ciencias administrativas. 4; 67-82. Recuperado de https://n9.cl/vdjq.

Pereira-Pérez, Z. (2011). Los diseños de método mixto en la investigación en educación: Una experiencia concreta. [Mixed-method designs in educational research: A concrete experience]. Revista Electrónica Educare Vol. XV, $N^{\circ} 1,15$. Recuperado de https://n9.cl/pozuw

Rodríguez-Jiménez, A., \& Pérez-Jacinto, A. (2017). Métodos científicos de indagación y de construcción del conocimiento. [Scientific methods of inquiry and knowledge construction]. Revista Escuela De Administración De Negocios, (82), 175-195. https://doi.org/10.21158/01208160.n82.2017.1647 
Karina Monserrath Siguenza-Peñafiel; Juan Carlos Erazo-Álvarez; Cecilia Ivonne Narváez-Zurita

Silva Guerra, H., González Ortiz, J., Martínez Díaz, D., Giraldo Oliveros, M., \& Juliao Esparragoza, D. (2014). Marketing: Conceptos y Aplicaciones. [Marketing: Concepts and Applications]. Universidad del Norte. Barranquilla, Colombia.

Silva, H., González, J., Martínez , D., Giraldo, M., \& Juliao, D. (2014). Markeying Conceptos y Aplicaciones. [Marketing Concepts and Applications]. Barranquillas, Colombia: Universidad del Norte. Recuperado el 13 de Octubre de 2018

Trelles-Méndez, E. M., Erazo-Álvarez, J. C., \& Narváez-Zurita, C. I. (2019). La influencia de las 4Ps en el Marketing Digital para la Cooperativa de Ahorro y Crédito JEP. [The influence of the 4Ps in Digital Marketing for the JEP Savings and credit cooperative.]. Revista Arbitrada Interdisciplinaria Koinonía, 180-205. http://dx.doi.org/10.35381/r.k.v4i1.455

Vega, M., Paz, S., \& Basantes, J. (2014). Branding y Propuesta Mercadológica para la constructura paz en la provincia de Imbabura. [Branding and Marketing Proposal for the peace builder in Imbabura province.]. Recuperado de https://n9.cl/r370

Villa-Pugo, M., Erazo-Álvarez, J., Narváez-Zurita, C., \& Erazo-Álvarez, C. (2019). EI Business Intelligence como estrategia de Marketing Digital aplicado en Agencias de Viaje. [Business Intelligence as a Digital Marketing Strategy applied in Travel Agencies]. CIENCIAMATRIA, 5(1), 328-360. https://doi.org/10.35381/cm.v5i1.270 